\title{
Fruktosaren kontsumoak eragin ditzakeen osasun-arazoak: konponbidea arazo bihurtzen denean
} (Health problems that may derive from fructose consumption:
when the solution becomes the problem)

\author{
Iñaki Milton-Laskibar*, Irene Besné, Helen Carr-Ugarte, María Puy Portillo \\ Farmazia eta Elikagaien Zientziak Saila. Farmazia Fakultatea, \\ Euskal Herriko Unibertsitatea (UPV/EHU), Vitoria-Gasteiz \\ Bioaraba Osasunaren ikerketa zentroa, Vitoria-Gasteiz \\ CIBERobn, Carlos III Osasun Institutua. Madril
}

\begin{abstract}
LABURPENA: Obesitatea lehen mailako osasun-arazotzat hartzen da, epidemia baten tamaina hartuz eta mundu-mailan heriotza goiztiarren eragile nagusietakoa bihurtuz. Gaixotasun metaboliko kroniko honen ezaugarri nagusietako bat berarekin lotzen diren osasun-arazoak dira, eta horien artean 2 motako diabetesa nabarmentzen da. Obesitatearen kasuan bezala, diabetesaren tratamendurako ere murrizketa kalorikoan oinarritutako dietak erabili ohi dira. Hala ere, tratamendu mota horrek arrakasta baxua lortu ohi duenez, bestelako esku-hartzeak ere beharrezkoak dira, eta horien artean sakarosa fruktosarekin ordezkatzea sarritan preskribatzen da paziente horientzat. Izan ere, glukosarekin ez bezala, fruktosaren metabolismorako ez da intsulinarik behar, eta ondorioz, ez da odoleko glukosa-mailen handipenik gertatzen. Hala ere, azken urteetan izan den fruktosaren kontsumoaren handipena gaixotasun metaboliko ezberdinen prebalentziaren handipenarekin batera gertatu denez, arreta handia jarri zaio fruktosari, konponbidea izan beharrean arazoa izan daitekeela uste delako. Esaterako, ikusi da fruktosaren gehiegizko kontsumoak edo kontsumo kronikoak gibel gantzatsu ez-alkoholikoa (GGEA) sortzen duela, de novo lipogenesia aktibatuz, gibeleko gantz-azidoen (GA) oxidazioa murriztuz eta hesteko mikrobiotaren konposizioa aldatu eta iragazkortasuna handituz, besteak beste. Horretaz gain, paradoxikoki fruktosaren gehiegizko kontsumoa intsulinaren erresistentziarekin (IR) ere lotu da. Kasu horretan, pankreako intsulina-jario handiagotua eta gibeleko IR deskribatu dira mekanismo eragile nagusitzat. Azkenik, fruktosaren gehiegizko kontsumoak edo kontsumo kronikoak erraietako gantz-ehunaren (EGE) gehiegizko metaketa eta dislipemiak ere eragin ditzakeela deskribatu da ikerlan ezberdinetan. Horiek horrela, nahiz eta hasiera batean fruktosaren kontsumoa osasungarritzat eta zenbait osasun-asalduraren «konponbidetzat» jo, argi geratzen da haren kontsumo desegokiak zenbait arrisku ere badituela. Ondorioz, beharrezkotzat jotzen da administrazioaren esku-hartzea fruktosaren kontsumoa murrizten edota erregulatzen lagunduko duten arauen garapenerako.

HITZ GAKOAK: Fruktosa, obesitatea, diabetesa, gibel gantzatsu ez-alkoholikoa.
\end{abstract}

ABSTRACT: Obesity is considered a major health problem, reaching epidemic magnitude and being one of the main causes of early deaths worldwide. Among the main features of this chronic-metabolic disease is its relationship with other metabolic conditions, being type 2 diabetes one of the most important ones. As for obesity, caloric-restriction is commonly used as therapeutic approach for diabetes. Nevertheless, since such treatments tend to reach low success, further interventions as sucrose replacement by fructose are widely used for these patients. Indeed, insulin is not necessary for fructose metabolism (unlike glucose), which occurs without changes in plasma glucose levels. Nevertheless, since the recent increase in fructose consumption occurred concomitantly with the prevalence increase of different metabolic disorders, much attention has been paid to this sugar, now considered the problem rather than the solution. For instance, excessive and/or chronic fructose consumption has been linked to non-alcoholic fatty liver disease (NAFLD), mainly due to de novo lipogenesis activation, hepatic fatty-acid (FA) oxidation reduction, and gut microbiota composition and intestinal permeability impairments. Paradoxically excessive fructose consumption has also been related to insulin resistance (IR), being enhanced pancreatic insulin secretion and hepatic IR as the main underlying mechanisms. Finally, according to different studies, excessive and/or chronic fructose consumption can also induce excessive visceral adipose tissue (VAT) accumulation and dyslipidemia. Altogether, although once fructose consumption was considered healthy and the «solution» for different health alterations, its inadequate consumption also involves some risks. Therefore, administrations' intervention is necessary to develop laws to reduce or regulate fructose consumption.

KEYWORDS: Fructose, obesity, diabetes, non-alcoholic fatty liver disease.

\footnotetext{
* Harremanetan jartzeko / Corresponding author: Iñaki Milton Laskibar. Farmazia eta Elikagaien Zientziak Saila. Farmazia Fakultatea. Unibertsitate Pasealekua 7 (01006 Vitoria-Gasteiz). - inaki.milton@ehu.eus - https://orcid.org/

Nola aipatu / How to cite: Milton-Laskibar, Iñaki; Besné, Irene; Carr-Ugarte, Helen; Portillo, María Puy (2021). «Fruktosaren kontsumoak eragin ditzakeen osasun-arazoak: konponbidea arazo bihurtzen denean». Ekaia, 41, 2021, 109-126. (https://doi.org/10.1387/ekaia.22707).
}

Jasotze-data: 2021, apirilak 12; Onartze-data: 2021, maiatzak 13.

ISSN 0214-9753 - eISSN 2444-3581 / (c) 2021 UPV/EHU

(7) $\odot$ Lan hau Creative Commons Aitortu-EzKomertziala-LanEratorririkGabe 4.0 Nazioartekoa lizentzia baten mende dago 
Iñaki Milton-Laskibar, Irene Besné, Helen Carr-Ugarte, María Puy Portillo

\section{SARRERA}

Obesitateak azken hamarkadetan izan duen bilakaera dela eta, gaur egun lehen mailako osasun-arazotzat jotzen da. Izan ere, obesitatearen prebalentziaren etengabeko handitzea dela eta, «XXI. mendeko epidemia» izena eman zaio. Gaixotasun hori da, gainera, mundu-mailan gertatzen diren heriotza goiztiarren eragile nagusietakoa [1]. Nahiz eta obesitatea faktore anitzeko gaixotasuntzat jotzen den, ingurumen-faktoreak eta elikatze-ohitura desegokiak (bizimodu sedentarioa eta gehiegizko energia kontsumoa, hurrenez hurren) nabarmentzen dira gaixotasunaren eragile nagusitzat [2]. Izan ere, obesitatea denboran mantentzen den energia kontsumoaren eta gastuaren arteko desorekatik sortzen da, eta osasunerako kaltegarria izan daitekeen gehiegizko gorputz-gantzaren metaketak ezaugarritzen du [3]. Nahiz eta, hasiera baten, energia-soberakinak biltegiratzeko mekanismo hau abantaila ebolutiboa izan gizakiarentzat, baditu onuragarriak ez diren beste ondorio batzuk ere [4].

Izan ere, obesitatearen ezaugarri nagusietako bat berarekin lotzen diren osasun-arazoak dira, eta horien prebalentzia obesitatearen prebalentziarekin batera handitu da [5]. Gaixotasun horien artean, 2 motako diabetesa (T2D) nabarmentzen da, zeina estuki lotua dagoen obesitatearekin (zenbatesten da T2D duten pazienteen \% 60-90 obesoak direla). Diabetesa garatu aurreko urratsa intsulinarekiko erresistentzia da, eta hori, berriz, obesitate-mailarekin eta gehiegizko gantz-metaketa dagoen eremuarekin (bereziki erraietako gantzarekin) erlazionatuta dago [6]. Obesitatearen kasuan bezala, T2Da pertsona baten bizi-kalitatean eragiten duen faktorea izateaz gain, heriotza goiztiarren eragilea ere bada [7]. Kontuan izanik T2D duten pertsonen gehiengoa obesoak izaten direla, normalean tratamendu berdinak preskribatzen dira bi gaixotasunentzat. Tratamendu horien artean, kaloria-murrizketa (dieta hipokaloriko orekatu batean oinarritua) izaten da ohiko aukera gorputz-pisuaren eta odoleko glukosa-mailen murrizketa lortzeko [8]. Kaloria-murrizketan edota karbohidratoen banaketa zehatzetan oinarritutako dietez gain, badira beste erreminta terapeutikoak ere T2D duten pazienteekin erabiltzen direnak. Horien artean sakarosa edo etxeko azukre arrunta (lotura glukosidikoz elkartutako glukosaz eta fruktosaz osatutako disakaridoa) gozagarri ez-nutritiboengatik ordezkatzea izaten da aukera bat, zeinak mahaiko azukreak baino ahalmen gozagarri handiagoa baitute kaloria ekarpen baxuagoarekin [9]. Aurrekoez gain, aspalditik erabili den sakarosaren beste ordezkoa fruktosa izan da, zeinak, glukosak ez bezala, ez duen intsulinarik behar xurgatua/metabolizatua izateko, eta, ondorioz, ez duen odoleko glukosa-mailen handipenik eragiten [10]. Hori dela eta, fruktosa sakarosa baino osasuntsuagoa ote den ustea zabaldu da, eta horrek, berriz, fruktosaren kontsumoaren handipena eragin du [11]. Fruktosa-kontsumoaren handipena gaixotasun metaboliko ezberdinen prebalentziaren handipenarekin batera gertatu denez, arreta handia jarri zaio fruktosari, obesi- 
tatearen eta harekin lotutako osasun-arazoen konponbidea izan beharrean arazoa izan daitekeela uste delako [11]. Kontuan izan behar da artikulu honetan fruktosaren kontsumoa aipatzen denean, elikagai eta elikagai-produktuei gehitutako fruktosari egiten zaiola erreferentzia. Izan ere, fruktosa naturalki aurkituko dugu frutetan, baina kasu horretan edukia baxua izateaz gain, elikagai horiek duten zuntzarekin batera irensten da. Hori dela eta, iturri dietetiko horretatik hartutako fruktosak ez ditu ondoren aipatuko diren osasun-asaldurak eragingo.

Testuinguru horretan, berrikuspen artikulu honen helburua da gehiegizko fruktosa kontsumoarekin gertatzen diren osasun-arazo ohikoenak zein diren azaltzea eta horiek bideratzen dituzten mekanismoetan sakontzea. Horretarako, gaur egungo fruktosa-kontsumoa ere aztertuko da, arazoaren benetako larritasuna ulertu ahal izateko.

\section{FRUKTOSA SAKAROSAREN ORDEZKO GISA: GAUR EGUNGO KONTSUMO-JOERA ETA TESTUINGURU METABOLIKOA}

Artikulu honen sarrera atalean aipatu den bezala, fruktosaren erabilera ohikoa izaten da/zen T2D duten pazienteen artean, haren metabolismorako intsulinarik behar ez delako. Horrek, halaber, fruktosaren kontsumoa sakarosaren (mahaiko azukrearen) kontsumoa baino osasuntsuagoa edo seguruagoa delako ustea zabaltzea eragin du $[10,11]$. Testuinguru horretan, elikagai-industriak egoera hori aprobetxatu du diabetesa duten pazienteei zuzendutako produktuak merkaturatzeko, zeinak sakarosa fruktosarekin ordezkatu baitute. Horiez gain, beste hainbat elikagai zein elikagai-produkturen osaera ere aldatu du, gantzetatik eratorritako kaloriak guztiz edo partzialki fruktosa bezalako azukre finduekin ordezkatuz. Horretarako, fruktosatan aberatsa den arto-xarabea (HFCS) izaten da gehien erabiltzen den gozagarria, zeina freskagarri, esneki fresko eta gosariko zerealetan erabiltzen baita osagaitzat [12]. Elikagai-industriak fruktosa osagai gisa erabiltze horrek fruktosa-kontsumoaren gorakada nabarmena eragin du [13]. Kontuan hartu behar da, gainera, freskagarrietan fruktosa osagaitzat erabiltzeak zenbait adin-talde zaurgarriago bihurtzen dituela gehiegizko fruktosa-kontsumoa pairatzeko, eta horien artean haur eta nerabeak nabarmentzen dira [14].

Nahiz eta hasiera batean fruktosa obesitatearen eta hari lotutako osasun-arazoen konponbidetzat jo, datuek erakusten dute fruktosa-kontsumoaren gorakada hainbat gaixotasun metabolikoren prebalentziaren gorakadarekin batera gertatu dela [13]. Itxurazko kontraesan hori hobeto ulertzeko, beharrezkoa da fruktosaren metabolismoak dituen ezaugarri nagusiak kontuan hartzea. Horrela, behin fruktosa gorputzera sartzen denean, hestean 
xurgatzen da nagusiki 5. glukosa garraiatzailearen (GLUT 5) bidez, zeina enterozitoen argiko mintzean espresatzen baita eta fruktosarekiko afinitate altua baitu [15]. Hestean xurgatu ondoren, odoleko fruktosa gehiena gibelak erauzten du porta-benako odoletik, nagusiki 2. glukosa garraiatzaileak (GLUT 2) bideratzen duen prozesuan [15] (1. irudia).

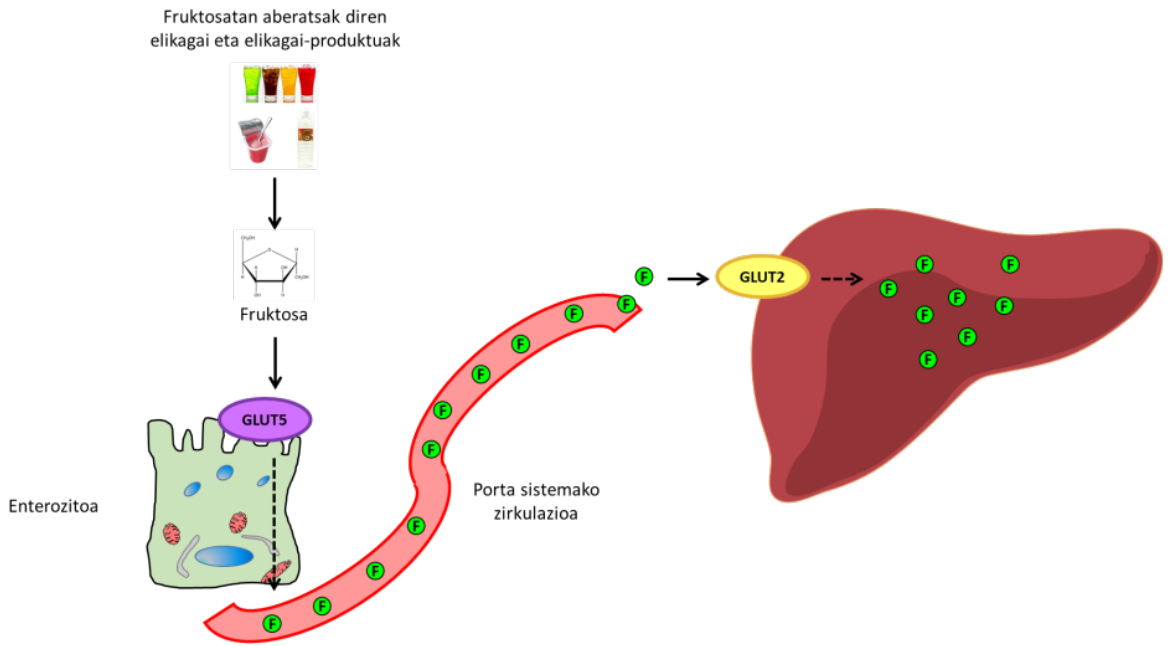

1. irudia. Hesteko fruktosaren xurgapena eta ondorengo gibelerako igarotzea. F: fruktosa, GLUT2: 2. glukosa garraiatzailea, GLUT5: 5. glukosa garraiatzailea.

Honaino, glukosaren eta fruktosaren metabolismoen artean dagoen alde nagusia (intsulinaren beharraz gain), gibelak egiten duen fruktosaren argipen altuagoa da (glukosarekin alderatuta) [15]. Hala ere, fruktosaren gehiegizko kontsumoak edota kontsumo kronikoak eragiten dituen arazoak hemendik aurrera datoz. Horrela, lehen urratsa ketohexokinasa entzimak (KHK) eragindako fruktosaren fosforilazioa da, zeinak fruktosa-1-fosfatoa (F1P) sortzen baitu. Fruktosaren metabolito horrek, prozesu metaboliko ezberdinen substratua izateaz gain, zenbait seinaleztapen-funtziotan ere parte hartzen du. Esaterako, fruktosaren xurgapen eta fosforilazio azkarrak gibeleko fosfatoaren xahutzea eragin dezake, azido urikoaren ekoizpena handituz. Bestalde, ikusi da fruktosaren kontsumoak purinen ekoizpena ere handitu dezakeela, zeina azido urikoaren sintesirako erabiltzen den substratua baita. Hori dela eta, fruktosaren gehiegizko kontsumoak edota kontsumo kronikoak zirkulazioko azido uriko mailaren handipena eragin dezake, eta ondorioz, arrisku-faktorea izan hezueria garatzeko [15]. Aurrekoez gain, nabarmendu behar da fruktosaren kontsumoak gaixotasun metabolikoen garapenarekin duen lotura, azukre horrek gibeleko lipidoen metabolismoan duen eraginarekin erlazionatzen dela. Horren harira, fruktosa- 
ren metabolismotik eratorritako metabolitoak de novo lipogenesia izeneko prozesuan erabiltzen dira lipidoen sintesirako substratu den malonyl-AKo lortzeko [15]. Horretaz gain, fruktosaren metabolismotik eratorritako metabolitoak glizerola ekoizteko ere erabiliko dira, zeina triglizeridoak sintetizatzeko beharrezko osagaia baita.

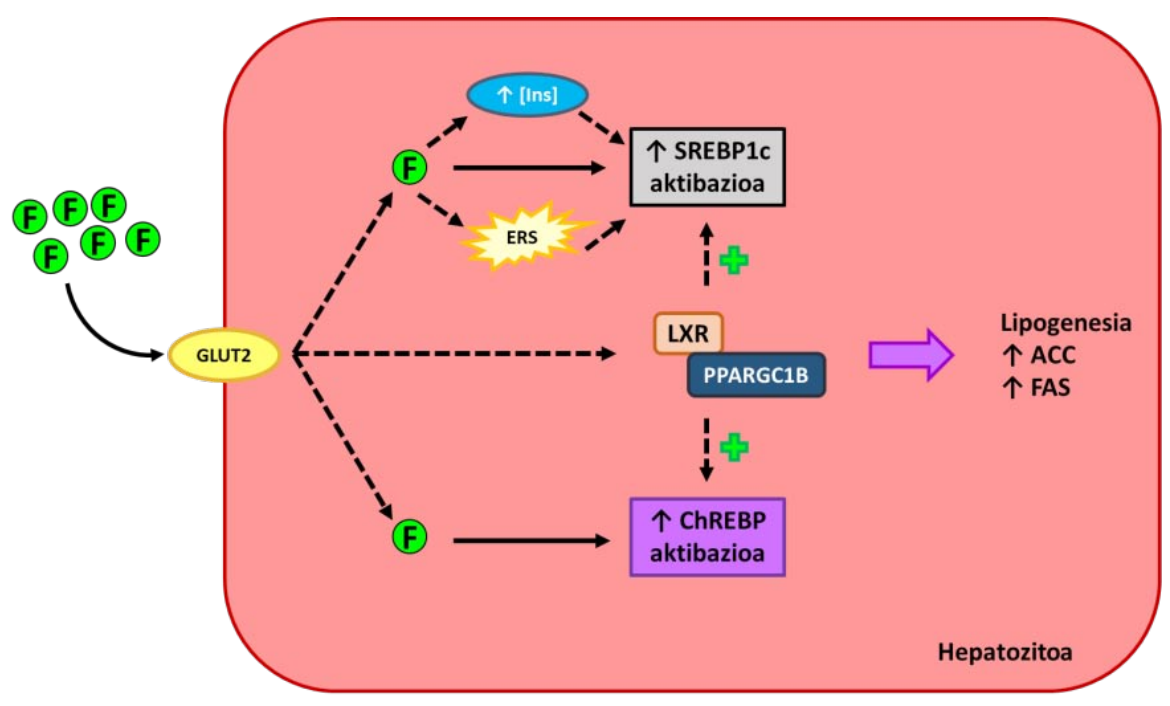

2. irudia. Fruktosak bideratutako erregulazioa gibeleko lipido-metabolismoan. ACC: azetil-AKo karboxilasa, ChREBP: karbohidratoen elementu erantzuleari lotzen zaion proteina, ERS: erretikulu endoplasmikoaren estresa, F: fruktosa, GA: gantz-azidoa, FAS: Gantz-azido sintasa, GLUT2: 2. glukosa garraiatzailea, Ins: intsulina, LXR: gibeleko X hartzailea, PPARGC1B: peroxisomen ugalketakaktibatutako gamma hartzailearen $1 \beta$ koaktibatzailea, SREBP1c: esterola doitzen duen elementura lotzen den 1c proteina.

Aurrekoez gain, fruktosaren gehiegizko kontsumoak edota kontsumo kronikoak esterola doitzen duen elementura lotzen den 1c proteina (SREBP1c) ere aktibatzen du, zuzenean edota fruktosak eragindako hiperintsulinemiaren bidez [15]. Nahiz eta, sarreran aipatu bezala, egoera fisiologikoan fruktosaren metabolismorako intsulinarik ez den behar, azukre horren gehiegizko kontsumoak glukagoiaren antzeko 1 peptidoaren (GLP-1) mailak handitzen ditu, zeinak, halaber, pankreako intsulina jarioa areagotzen baitu eta hiperintsulinemia eragin [16]. Are gehiago, ikusi da fruktosak SREBP1c proteinaren zatiketa eragiten duela. Nabarmendu behar da transkripzio-faktore horren aktibaziorako beharrezkoa dela aurrez aipatutako zatiketa. Fruktosaren kasuan, SREBP1c-aren zatiketa/aktibazioa bi modutan eragingo du: zuzenean, edota erretikulu endoplasmikoaren es- 
Iñaki Milton-Laskibar, Irene Besné, Helen Carr-Ugarte, María Puy Portillo

tresaren (ERS) handipena eraginez [15]. Baina SREBP1c-az gain, fruktosak karbohidratoen elementu erantzuleari lotzen zaion proteina (ChREBP) ere aktibatzen du (aktibazio sendoa), zeinak, halaber, de novo lipogenesian parte hartzen duten entzimak erregulatzen dituen, karbohidratoetatik eratorritako metabolitoak lipidoen sintesiarekin lotuaz [15]. Horretaz gain, ChREBP-a ere gai da lipidoen oxidazioa oztopatzeko peroxisomen ugalketak aktibatutako $\alpha$ hartzailea (PPAR $\alpha$ ) antagonizatuz, zeina lipidoen oxidazioa erregulatzen duen transkripzio faktorea baita [17]. Nahiz eta SREBP1c and ChREBP izan de novo lipogenesiko transkripzio faktore nagusienak, fruktosak horien efektuak handitzen dituzten beste transkripziofaktoreak ere aktiba ditzake, hala nola gibeleko X hartzailea (LXR) eta peroxisomen ugalketak-aktibatutako gamma hartzailearen $1 \beta$ koaktibatzailea (PPARGC1B) [18] (2. irudia).

\section{FRUKTOSAREN GEHIEGIZKO KONTSUMOAK EDOTA KONTSUMO KRONIKOAK ERAGITEN DITUEN OSASUN-ARAZOAK}

Nahiz eta, berrikuspen artikulu honen aurreko ataletan aipatu den bezala, hasiera baten fruktosa sakarosaren ordezko gisa gomendatua izan paziente diabetikoentzat, ikerlan ezberdinek erakutsi dute azukre horren gehiegizko kontsumoak edota kontsumo kronikoak bere arriskuak ere badituela. Ondorengo azpiataletan fruktosarekin gehien erlazionatzen diren osasun-arazoak aztertuko dira, eta horiek bideratzen dituzten mekanismoetan sakonduko da.

\subsection{Gibel gantzatsu ez-alkoholikoa}

Gibel gantzatsu ez-alkoholikoa (GGEA) fruktosaren gehiegizko kontsumoarekin edota kontsumo kronikoarekin lotu den beste osasun-arazoa da. Gibel-asaldura honen ezaugarria da organo horretan ematen den gehiegizko lipido-metaketa alkohol kontsumoa $30 \mathrm{~g}$ /egunetik beherakoa denean. Esteatosia da GGEAren formarik onberarena, zeina gibeleko triglizeridoedukia organoaren pisuaren $\geq \% 5$ denean, edota hepatozitoen $\geq \% 5 \mathrm{ak}$ triglizerido-metaketa erakusten duenean diagnostikatzen den [19]. Nahiz eta berez esteatosia ez den osasunerako arriskutsutzat jotzen den gibel-asaldura, duen arrisku nagusia da larriagoak diren egoeretara jo dezakeela, hala nola esteatohepatitis ez-alkoholikoa (GEEA), zirrosia edo gibeleko minbizia. Aurrez aipatu den bezala, elikagaien ekoizpenerako gantzak fruktosarekin ordezkatzeak azken horren kontsumoaren igoera eragin du, zeina GGEAren prebalentziaren gorakadarekin batera gertatu den. Izan ere, GGEAren prebalentzia etengabe hazi da azken hamarkadetan, gaur egun munduko biztanleriaren $\% 25 \mathrm{i}$ eraginez, eta ondorioz, gibeleko gaixota- 
sun kronikoen kausa nagusia izatera iritsi da [20]. GGEAren agerpenean edota garapenean eragiten duten faktoreen artean fruktosaren kontsumoa aho batez onartzen da kausa nagusienetakotzat [21]. Horren harira, fruktosatan aberastutako edari freskagarrien kontsumoak pisu nabarmena du eguneko fruktosa kontsumoaren igoeran, eta, ondorioz, GGEAren prebalentziaren hazkuntzan [11].

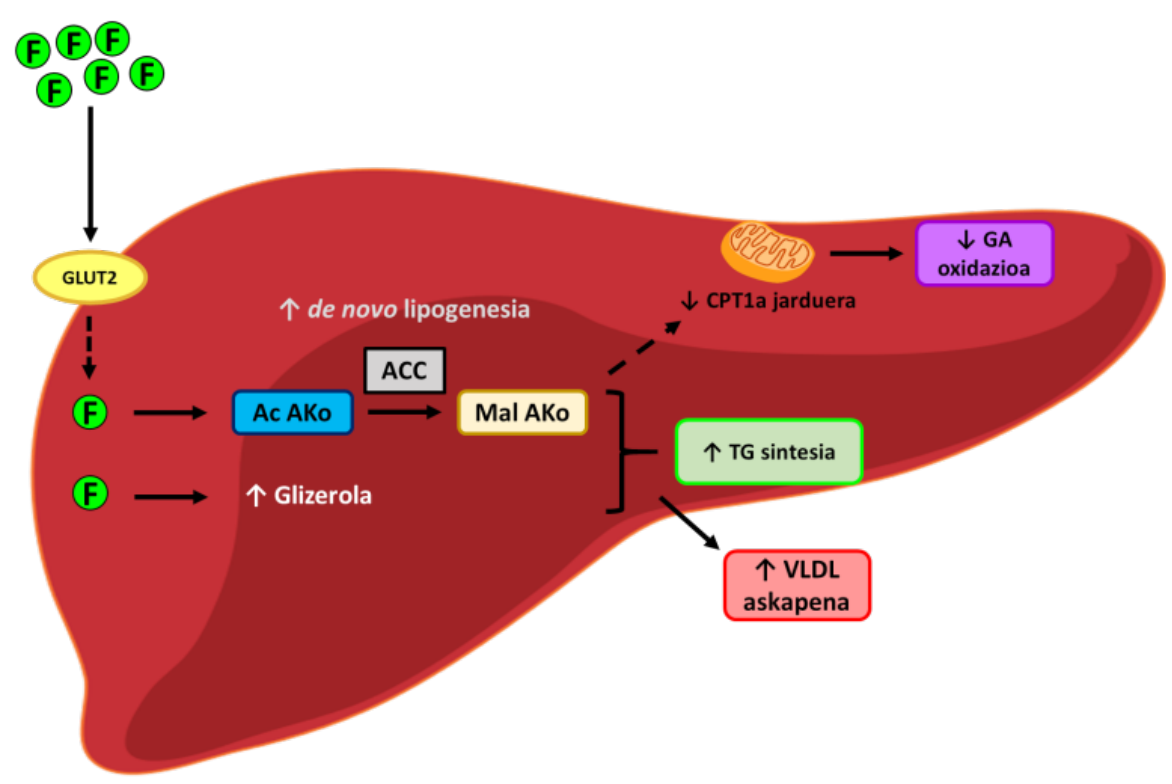

3. irudia. Fruktosaren papera gibeleko lipido-metabolismoan. ACC: azetil-AKo karboxilasa, Ac AKo: azetil-AKo, CPT1a: 1a karnitina aziltransferasa, F: fruktosa, GA: gantz-azidoa, GLUT2: 2. glukosa garraiatzailea, Mal AKo: malonyl-AKo, TG: triglizeridoa, VLDL: dentsitate oso baxuko lipoproteinak.

Nahiz eta hainbat diren GGEAren garapenean eragin dezaketen mekanismoak, de novo lipogenesia da nagusiki fruktosaren gehiegizko kontsumoak edota kontsumo kronikoak eragiten diona. Artikuluaren sarreran azaldu den bezala, fruktosaren metabolismoa nagusiki gibelean gertatzen da, non gehiegizko fruktosa kontsumoak de novo lipogenesia aktibatzen baitu. Izatez, de novo lipogenesia erreakzio-segida bat da, non lipidoak sintetizatzen diren karbohidratoak bezalako substratuetatik abiatuta [15]. Glukosarekin gertatzen den bezala, fruktosaren metabolismoko azken produktua pirubatoa da. Behin mitokondrio barrura sartuta, pirubatoa azetil-AKo bihurtzen da, eta azken hau, berriz, azido trikarboxilikoaren ziklora (TCA) igarotzen da energia ekoizteko [18]. Aitzitik, gehiegizko fruktosa-kontsumoa dagoen egoeretan, TCA ase daiteke, eta, ondorioz, azetil-AKo pi- 
Iñaki Milton-Laskibar, Irene Besné, Helen Carr-Ugarte, María Puy Portillo

laketa bat gertatu. Hori gertatzen denean, azetil-AKo karboxilasa (ACC) entzimak (de novo lipogenesiko entzima mugatzailea) azetil-AKo-a malonyl-AKo bihurtzen du. Ondoren, gantz-azido sintasa (FAS) entzimak malonyl-AKo-a erabiliko du substratu gisa palmitatoa sintetizatzeko (de novo lipogenesiko produktu nagusia) [22]. Bestalde, gehiegizko fruktosa-kontsumoak eragindako de novo lipogenesiaren aktibazioak malonyl-AKoaren metaketa ere eragin dezake. Hori gertatzen denean, gantz-azidoen oxidazioa murriztu edo eten daiteke, malonyl-AKo-a GAk mitokondriora sartzeaz arduratzen den 1a karnitina aziltransferasa (CPT1a) entzimaren inhibitzailea baita [22]. Aurrekoez gain, fruktosa-kontsumo altuak glukolisiaren bitartekarien pilaketa ere eragin dezake, zeinak glizerol-3-fosfato bihur daitezkeen. Horiek, berriz, triglizeridoen sintesian erabili ahalko dira [23]. Nabarmendu behar da, gainera, fruktosa gai dela entzima lipogenikoak aktibatu edota GAen oxidazioa bideratzen duten entzimak inhibitzen dituzten transkripzio-faktoreak aktibatzeko ere. Prozesu horiek guztiek gibeleko lipido ekoizpenaren eta oxidazioaren arteko desoreka sor dezakete, eta lipido-pilaketa eragin organo horretan (3. irudia).

Nahiz eta, oro har, GGEAn gertatzen den gehiegizko gantz-metaketa triglizerido moduan gertatu, azpimarratu behar da osasun-asaldura hori fruktosaren gehiegizko kontsumoak edota kontsumo kronikoak sortua denean, bestelako lipido-espezieak ere metatzen direla gibelean. Horrela, berriki karraskarietan eginiko ikerlan batean ikusi da gantz-aseetan eta fruktosatan aberatsa den dietarekin (energia-ekarpenaren \% 40 eta \% 22 gantz eta fruktosa gisa, hurrenez hurren) elikatutako arratoiek GGEA garatzen dutela, neurri handi batean gantza gibelean diglizerido eran metatzen dutelako [24]. Izan ere, ikerlan horretan ikusi zuten, fruktosatan aberatsa zen dietak arratoi horien gibeletan de novo lipogenesiaren aktibazioa eragiteaz gain, triglizeridoen muntaia bideratzen duen 2 diazilglizerol aziltransferasa (DGAT2) entzimaren proteina-espresioa ere murrizten zuela. Ondorioz, gantzaren zati bat diglizerido eran geratuko da eta gibelean metatu.

Bestalde, fruktosaren gehiegizko kontsumoak edota kontsumo kronikoak gibelean oxidazio-estresa ere sortuko du, zeina GGEAren bilakaeran garrantzi handia duen prozesua baita [25]. Testuinguru horretan, gibeleko gehiegizko gantz-metaketak erradikal askeen ekoizpen handiagotua sortuko du, zeina ezin izango baita sistema antioxidatzailearen bidez konpentsatu [26]. GGEAn ekoiztu diren erradikal askeek hainbat molekularekin erreakziona dezakete, eta lipidoen oxidazio-produktuak sortu. Horien artean malondialdehidoa (MDA) eta 4-hidroxinonenala (4HNE) nabarmentzen dira, zeinak esteatohepatitis ez-alkoholikoaren garapenean paper garrantzitsua duten konposatuak baitira [26].

Kontuan izan behar da, ordea, fruktosaren eta GGEAren arteko lotura ez dela azukre horrek gibelean bertan sortzen dituen efektuetara mugatzen. Izan ere, fruktosatan aberatsak diren dietekin elikatutako karraskarietan 
ikusi denez, azukre horrek asaldurak sortzen ditu bai hesteko mikrobiotaren konposizioan bai hestearen iragazkortasunean ere [27]. Horren harira, hesteko mikrobiotaren disbiosia (fruktosa kontsumo altua dagoenean gertatzen dena, adibidez) GGEArekin zein GEEArako bilakaerarekin lotu da. Ikerlan ezberdinek erakutsi dutenaren arabera, fruktosak hestean eragindako asaldura horiek kate laburreko GAen sintesia, behazun-gatzen ekoizpena eta etanolaren sintesi endogenoa aztoratzen ditu, eta horiek, berriz, aurrez aipatutako gibel-asalduren eragileak izango lirateke [28].

\subsection{Intsulinarekiko erresistentzia}

Paradoxikoki, intsulinarekiko erresistentzia (IR) da fruktosaren gehiegizko kontsumoak edota kontsumo kronikoak eragiten duen osasun-arazoetako bat. Nahiz eta fruktosak eragindako IRri buruz egindako ikerlanak urriak izan, badira zenbait egile fruktosaren kontsumoak glukosaren homeostasian dituen eraginak aztertu dituztenak. Testuinguru horretan, nabarmendu behar da ikerlan horiek guztiek fruktosaren kontsumoak IR garatzeko arriskua handitzen duela ondorioztatzen dutela (1. taula). Kontuan hartu behar da, gainera, efektu horiek freskagarriak kontsumitzen dituzten nerabeetan ere ikusi direla, zeina adin-talde horretan ohikoa den kontsumo ohitura baita. Ikerlan horretan ikusi zen fruktosaren kontsumoak obesoak ez ziren nerabeetan eragiten zuen intsulina-mailen igoera ez zela taldekide obesoetan gertatzen zena bestekoa [29].

1. taula. Fruktosak glukosaren homeostasian eta intsulinarekiko erresistentzian dituen eraginak aztertzen dituzten ikerlanak.

\begin{tabular}{|c|c|c|c|}
\hline Egilea & Partaideak & Baldintza esperimentalak & Behaketak \\
\hline [29] & $\begin{array}{l}\text { Nerabeak } \\
\text { (12-16 urte) }\end{array}$ & $\begin{array}{l}\text { Partaideak GAE kontsumoa- } \\
\text { ren arabera banatu ziren ez- } \\
\text { kontsumitzaile edo kontsu- } \\
\text { mitzaile (1-350, 351-750, eta } \\
>750 \text { mL/egun) taldeetan. } \\
\text { Partaideek } 2 \text { motatako } \\
\text { GAE-ak kontsumitzen zituz- } \\
\text { ten: } \\
\text { - Azukre guztia HCFS gisa } \\
\text { zutenak. } \\
\text { - Azukrearen gehiengoa na- } \\
\text { gusiki sakarosa gisa zute- } \\
\text { nak. }\end{array}$ & $\begin{array}{l}\text { Kontsumitzaileak ez zirene- } \\
\text { kin alderatuta, azukre guztia } \\
\text { HCFS gisa zuten }>350 \mathrm{~mL} \\
\text { GAE/egun hartzen zuten par- } \\
\text { taideetan HOMA1-IR eta } \\
\text { HOMA2-IR balio altuagoak } \\
\text { aurkitu ziren. } \\
\text { Azukre guztia HCFS gisa zu- } \\
\text { ten GAE-ak kontsumitzen zi- } \\
\text { tuzten partaide obesoetan IR } \\
\text { aurkitu zen bitartean, talde- } \\
\text { kide ez-obesoetan ez zen ho- } \\
\text { rrelakorik ikusi. }\end{array}$ \\
\hline
\end{tabular}


Iñaki Milton-Laskibar, Irene Besné, Helen Carr-Ugarte, María Puy Portillo

\begin{tabular}{|c|c|c|c|}
\hline Egilea & Partaideak & Baldintza esperimentalak & Behaketak \\
\hline$[30]$ & $\begin{array}{c}\text { Gizonezko } \\
\text { osasuntsuak } \\
(18-65 \text { urte }) \\
\text { GMI: }<30 \mathrm{~kg} / \mathrm{m}^{2}\end{array}$ & $\begin{array}{l}\text { Parte-hartzaileak } 2 \text { taldetan } \\
\text { banatu ziren eta pisua man- } \\
\text { tentzeko dietak jaso zituzten } \\
18 \text { egunetan: } \\
\text { - Talde batek HFD dieta } \\
\text { (energiaren \% 20-25 fruk- } \\
\text { tosa gisa) jaso zuen } 9 \text { egu- } \\
\text { nez eta ondoren CCHO } \\
\text { dieta (energiaren \% } 5 \\
\text { fruktosa gisa) jaso zuen } \\
9 \text { egun gehiagoz. } \\
\text { - Beste taldeak dieta berdi- } \\
\text { nak jaso zituen, iraupen } \\
\text { berarekin, baina kontrako } \\
\text { ordenean. }\end{array}$ & $\begin{array}{l}\text { Aste betez HFD dieta hartzeak } \\
\text { gibeleko IR eragin zuen, zeina } \\
\text { gibelak hiperintsulinemia- } \\
\text { egoeran mantentzen zuen glu- } \\
\text { kosa-ekoizpenetik ondorioz- } \\
\text { tatu baitzen. }\end{array}$ \\
\hline$[31]$ & $\begin{array}{c}\text { Gizonezko } \\
\text { osasuntsuak } \\
\text { (20-65 urte) } \\
\text { GMI: } 27-40 \mathrm{~kg} / \mathrm{m}^{2}\end{array}$ & $\begin{array}{l}\text { Partaideek } 75 \mathrm{~g} \text { fruktosa/ } \\
\text { egun hartu zituzten } 12 \text { aste- } \\
\text { tan. }\end{array}$ & $\begin{array}{l}\text { Ikerketaren hasieran bildutako } \\
\text { datuekin alderatuta, } 12 \text { astez } \\
\text { fruktosa kontsumitzeak ba- } \\
\text { rauko intsulina-maila altua- } \\
\text { goak eta HOMA-IR indizea- } \\
\text { ren balio altuagoak izatea } \\
\text { eragin zuen. }\end{array}$ \\
\hline$[32]$ & $\begin{array}{l}\text { Heldu osasuntsuak } \\
\quad \text { (29-66 urte) } \\
\text { GMI: } 29-40,99 \mathrm{~kg} / \mathrm{m}^{2}\end{array}$ & $\begin{array}{l}\text { Partaide guztiek \% 30-40ko } \\
\text { (Kkal/egun) murrizketa ka- } \\
\text { lorikoa jasan zuten } 24 \text { astez. } \\
\text { Denbora tarte horretan par- } \\
\text { taideak bi taldetan banatu zi- } \\
\text { ren: } \\
\text { - LFD taldea: Fruktosatan } \\
\text { aberatsak diren fruta eta } \\
\text { barazkiak, eta gehitutako } \\
\text { fruktosa zuten produktu- } \\
\text { rik gabeko dieta jarraitu } \\
\text { zuten. } \\
\text { - SD taldea: Ez zuten ja- } \\
\text { rraibiderik jaso azukredun } \\
\text { produktuak dietatik ken- } \\
\text { tzeko. }\end{array}$ & $\begin{array}{l}24 \text { asteren buruan, barauko } \\
\text { glukosa maila baxuagoa aur- } \\
\text { kitu zen LFD taldeko paratai- } \\
\text { deetan. }\end{array}$ \\
\hline
\end{tabular}

CCHO: karbohidrato konplexuetan aberatsa den dieta; GAE: gehitutako azukredun edariak; GMI: gorputz-masaren indizea; HCFS: fruktosatan aberatsa den arto jarabea; HFD: fruktosatan aberatsa den dieta; HOMA-IR: intsulinaren erresistentzia balioztatzeko modelo homeostatikoa; IR: intsuli- 
narekiko erresistentzia; LFD: fruktosatan baxua den dieta; SD: dieta estandarra.

Fruktosaren kontsumoak eragindako IR bideratzen duten mekanismoeragileei dagokienez, ikusi da fruktosak efektu desiragaitzak dituela gluzemiaren kontrolean parte hartzen duten ehunetan eta organoetan. Horrela, ikusi da behin fruktosa GLUT5 hartzaileak xurgatu eta odoleko GLP-1 mailak handitu ondoren, pankreako intsulina-jarioa areagotzen dela. Bestalde, handitutako odoleko GLP-1 maila horiek denboran mantentzen direnez (ordubete baino gehiagoz), fruktosaren kontsumoak hiperintsulinemia eragingo du [16]. Gertaera horien ondorioz, intsulina-maila altuekiko esposizio jarraitu bat gertatuko da, zeinak intsulina-hartzaileen jardueramurrizketa eragingo duen (fosforilazio bidez). Testuinguru horretan, proposatu da hiperintsulinemiak eragindako kitzikapen errepikakorrek intsulina-hartzaileen sentikortasun-galera eragiten dutela, eta ondorioz IR garatu daiteke [33]. Bestetik, fruktosaren metabolismoak eragiten duen gibeleko azido urikoaren ekoizpen altua ere IRrekin loturik dagoela proposatu da [34]. Izan ere, behin azido urikoa pankreako $\beta$-zeluletara sartzen denean, zelula-barneko oxigenoaren espezie erreaktiboen (ROS) maila handitu egiten da. Horren ondorioz, 2. intsulina-hartzailearen substratuaren (IRS2) serina hondarren fosforilazioa gertatuko da, zeinak B proteina kinasaren (Akt) fosforilazioa oztopatuko duen. Gertaera horiek guztiek glukosa xurgapenaren eta intsulina ekoizpenaren asaldura eragingo dute pankreako $\beta$-zeluletan, eta IR eragin [35].

Aurrekoez gain, ikusi da fruktosaren kontsumoak IR eragin dezakeela gibelean ere mekanismo ezberdinen bidez. Artikulu honen lehenbiziko ataletan aipatu bezala, fruktosa oso lipogenikoa den azukrea da, eta ondorioz gantz-azido askeen (GAA), diazilglizerolen, zeramiden eta azil-karnitinen sintesia areagotzen du gibelean, zeinak IRren bitartekariak baitira [36]. Gainera, gibeleko GAAen ekoizpen eta metatze handituak mitokondrioen disfuntzioa eragiten du. Ondorioz, gibeleko GAen oxidazioa murriztu egiten da, eta ROS ekoizpena, berriz, handitu, eta IR eragin. Izan ere, fruktosak, mitokondrioen funtzioa oztopatzeaz gain, organulu horien tamaina eta kopuru-murrizketa ere eragiten du [37]. Fruktosak eragiten duen beste ondorio bat, gibeleko IRrekin loturik dagoena, sistema immunearen asaldura da. Horren harira, ikerlan ezberdinek erakutsi dute fruktosaren kontsumoak gibelaren hantura eragiten duela zuzenean (hantura-zelulei eraginez eta hantura-eragileak diren zitokinen askapena handituz) edo zeharka, eta horrek, berriz, intsulinaren seinaleztapen-bidea oztopatzen du, glukosaren xurgapena asaldatuz eta IR sortuz [38]. Bestalde, ERSa ere aintzat hartu beharreko gertaera da fruktosak eragindako IRri dagokionez. Aurrekoez gain, fruktosak gibeleko autofagia murrizten duela ere deskribatu da ugaztunen rapamizina itua (mTOR) aktibatuz, zeinak IRren garapenean lagunduko duen [39]. 
Iñaki Milton-Laskibar, Irene Besné, Helen Carr-Ugarte, María Puy Portillo

\subsection{Erraietako gantz-ehunaren metaketa}

Erraietako gantz-ehunak (EGE), barrunbe abdominalean metatu eta bertako organoak inguratzen dituen gantz-ehunari egiten dio erreferentzia. EGEren ezaugarri nagusietakoa da gantz-ehun hori osatzen duten adipozitoak sarritan hipertrofikoak izaten direla, eta ondorioz, 6 eta 8 interleukinak (Il-6 eta IL-8, hurrenez hurren), 1. monozitoen proteina kimioerakarlea (MCP-1) edo $\alpha$ tumore nekrosi faktorea (TNF- $\alpha$ ) bezalako zitokina hanturaeragileak aska ditzakete [4]. Ondorioz, GA gehiago jariatzen dira odolera, zeinak gantz-ehuna ez diren ehunetara eta organoetara (gibela eta muskulu eskeletikoa nagusiki) hel daitezkeen, eta horrek GGEA edo IR bezalako asaldura metabolikoak sortuko ditu [4]. Nahiz eta EGEren metaketa, nagusiki, obesoak diren pertsonetan gertatzen den, nabarmendu behar da fruktosaren gehiegizko kontsumoak edota kontsumo kronikoak gantz-metaketa hori obesoak ez diren pertsonetan ere eragin dezakeela. Fenotipo horri, «argala kanpotik, obesoa barrutik» izena eman zaio (TOFI, ingelesez) [40].

EGEren metaketa bideratzen duten mekanismoei dagokionez, deskribatu da fruktosak zelula barneko glukokortikoide-kontzentrazioak aztora ditzakeela, gantz-ehuneko 1 motako $11 \beta$-hidroxiesteroide deshidrogenasaren (11ß-HSD1) mRNA- eta proteina-espresioa handituz. Horrek, glukokortikoideen gehiegizko aktibazioa eragiten du eta EGEaren metaketa eta horri lotutako asaldura metabolikoen agerpena faboratuko dira [41]. Bestalde, fruktosaren gehiegizko kontsumoak edota kontsumo kronikoak eragindako gibeleko triglizerido-ekoizpen handituak dentsitate oso baxuko lipoproteinen (VLDL) sintesia areagotzen du. Horren ondorioz, EGEak lipoproteina mota horretatik egiten duen triglizerido xurgapena handitzen du, gantz-gordailu horren hazkuntza eraginez [42]. Aurreko mekanismoez gain, fruktosaren gehiegizko kontsumoak edota kontsumo kronikoak eragindako IRak adiponektinarekiko erresistentzia sor dezake gibelean. Horrek, berriz, gibeleko lipogenesiaren handipena eragiten du, eta, beraz, gibeleko kaltea areagotu, eta EGEaren metaketa faboratuko dira [42].

\subsection{Dislipemiak}

Dislipemia da fruktosaren gehiegizko kontsumoak edota kontsumo kronikoak eragin dezakeen beste osasun-arazo bat. Definizioz, dislipemia izango litzateke odoleko lipido-espezie baten edo gehiagoren mailen aztoratzea [43]. Dislipemiak lotura estua du EGE metaketa eta IRrekin, asaldura metaboliko horietan ohikoa baita lipoproteina ezberdinen odoleko mailen asaldurak gertatzea. Ohikoena, kolesteroletan aberatsak diren dentsitate-baxuko lipoproteinen (LDL) mailen igoera edo/eta dentsitate-altuko lipoproteinen (HDL) mailen murrizketa gertatzea da [43]. Hori gertatzen denean, alde batetik LDLak bideratzen duen kolesterolaren ehunetarako garraioa handituko da, eta horrek, berriz, gaixotasun kardiobaskularren ga- 
rapena/larritzea eragin dezake. Bestalde, HDL maila murriztuen ondorioz, lipoproteina horrek bideratzen duen kolesterolaren ehunetatik gibelerako garraioa ere murriztuko da. Hori dela eta, fruktosaren gehiegizko kontsumoak edota kontsumo kronikoak eragiten dituen asaldura metabolikoek dislipemiaren garapena edo okertzea eragin dezakete, zeinak, halaber, gaixotasun kardiobaskularrak pairatzeko arriskua handitu dezaketen.

Fruktosak eragindako dislipemiaren garapenean parte hartzen duten mekanismoei dagokienez, aurrez aipatu den bezala, fruktosaren metabolismoak gibeleko de novo lipogenesia aktibatu eta lipidoen odolerako askapenaren handitzea eragiten du [4], zeinak IRrekin lotuta baitaude [44]. Gibelean metabolizatzen den bitartean, fruktosak azil-glizerol molekulen azil eta glizerol frakzioen ekoizpenerako substratuen kontrolik gabeko sintesia eragin dezake. Substratu horiek eta prozesu horretan sortzen den gehiegizko energia-fluxuak (kontrolik gabeko fruktosaren metabolismotik datorrenak) triglizeridoen gehiegizko ekoizpena faboratuko dute [45], zeinak VLDL molekulak sintetizatzeko erabiliko baitira kolina/etanolamina fosfotransferasa (CEPT) entzimak erregulatzen duen prozesuan. Kontuan izan behar da VLDLak triglizerido eta kolesteroletan aberatsak diren lipoproteinak direla, zeinak gibeletik irteten diren eta GA-ak eta kolesterola ehun ezberdinetara eramaten dituzten. Bestetik, handitutako VLDL mailez gain, HDL maila baxuak ere ohikoak izaten dira dislipemian. Izan ere, gibelera heltzen diren triglizeridotan aberatsak diren HDL molekulak lipasa edo proteina-lipasa entzimek hidrolizatuko dituzte, eta HDL hondarrak zirkulaziotik ezabatzen dira, eta lipoproteina horien mailen murrizketa gertatu. Horretaz gain, CEPT entzimak LDL molekulak triglizeridotan aberastea ere bideratzen du, kolesterol esterrak triglizeridoekin ordezkatuz [46].

Entsegu klinikoetan lortutako datuen arabera, gehiegizko fruktosa-kontsumoak odoleko triglizerido-mailen igoera eta HDL mailen murrizketa eragiten du [47]. Beraz, fruktosaren kontsumoak odoleko lipido-espezie ezberdinen mailetan eragin ditzakeen aldaketek gaixotasun kardiobaskularrak pairatzeko arriskua handitzea eragingo lukete.

\section{ONDORIOAK}

Gaurdaino ezagutzen diren datuetan oinarrituz, esan daiteke gaur egun egiten den fruktosaren kontsumoa onuragarria ez izateaz gain, zenbait gaixotasun metaboliko kroniko garatzeko arrisku faktorea ere badela. Kontuan hartzen bada, gainera, fruktosa eduki altuena duten elikagai eta elikagai-produktuak nagusiki haur eta nerabeek kontsumitzen dituztela, arreta berezia jarri beharko litzateke fruktosak adin-talde horietan sor ditzakeen efektuetan. Izan ere, nahiz eta artikulu honetan bildu diren fruktosaren kontsumoarekin lotutako osasun-arazoak banaka aztertu diren, litekeena da 
Iñaki Milton-Laskibar, Irene Besné, Helen Carr-Ugarte, María Puy Portillo

errealitatean aipaturiko gaixotasun horiek batera gertatzea. Bestalde, nabarmendu behar da artikuluan aipatu diren gaixotasun horietako zenbait larriagoak eta sendaezinak diren gaixotasun bihur daitezkeela, esaterako IR diabetes bihurtzea. Hori dela eta, osasun-administrazioaren esku-hartzea beharrezkotzat jotzen da fruktosaren kontsumoa murrizten edota erregulatzen lagunduko duten arauak garatzeko. Elikagai-industriari dagokionez, berriz, «osasungarriagoak» diren gozagarrien inguruko ikerketak egitea ezinbestekoa litzateke fruktosaren erabilera murriztu ahal izateko.

\section{BIBLIOGRAFIA}

[1] BLÜHER M. 2019. «Obesity: global epidemiology and pathogenesis». Nat Rev Endocrinol, 15, 288-298.

[2] HWALLA N. eta JAAFAR Z. 2021. «Dietary Management of Obesity: A Review of the Evidence». Diagnostics (Basel), 11, 24.

[3] WORLD HEALTH ORGANIZATION. «Obesity and overweight». 2021.

[4] LONGO M., ZATTERALE F., NADERI J., PARRILLO L., FORMISANO P., RACITI G.A., BEGUINOT F. eta MIELE C. 2019. «Adipose Tissue Dysfunction as Determinant of Obesity-Associated Metabolic Complications». Int J Mol Sci, 20, 2358.

[5] DAI H., ALSALHE T.A., CHALGHAF N., RICCÓ M., BRAGAZZI N.L. eta WU J. 2020. «The global burden of disease attributable to high body mass index in 195 countries and territories, 1990-2017: An analysis of the Global Burden of Disease Study». PLoS Med, 17, e1003198.

[6] ECKEL R.H., KAHN S.E., FERRANNINI E., GOLDFINE A.B., NATHAN D.M., SCHWARTZ M.W., SMITH R.J. eta SMITH S.R. 2011. «Obesity and type 2 diabetes: what can be unified and what needs to be individualized?». J Clin Endocrinol Metab, 96, 1654-1663.

[7] KHAN M.A.B., HASHIM M.J., KING J.K., GOVENDER R.D., MUSTAFA H. eta KAABI J.A. 2020. «Epidemiology of Type 2 Diabetes - Global Burden of Disease and Forecasted Trends». J Epidemiol Glob Health, 10, 107111.

[8] BHATT A.A., CHOUDHARI P.K., MAHAJAN R.R., SAYYAD M.G., PRATYUSH D.D., HASAN I., JAVHERANI R.S., BOTHALE M.M., PURANDARE V.B. eta UNNIKRISHNAN A.G. 2017. «Effect of a Low-Calorie Diet on Restoration of Normoglycemia in Obese subjects with Type 2 Diabetes». Indian J Endocrinol Metab, 21, 776-780.

[9] LOHNER S., TOEWS I., KUELLENBERG DE GAUDRY D., SOMMER H. eta MEERPOHL J.J. 2017. «Non-nutritive sweeteners for diabetesmellitus». Cochrane Database Syst Rev, 2017, CD012885.

[10] MALIK V.S. eta HU F.B. 2015. «Fructose and Cardiometabolic Health: What the Evidence from Sugar-Sweetened Beverages Tells Us». J Am Coll Cardiol, 66, 1615-1624. 
[11] BIDWELL A.J. 2017. «Chronic Fructose Ingestion as a Major Health Concern: Is a Sedentary Lifestyle Making It Worse? A Review». Nutrients, 9, 549.

[12] SOFTIC S., GUPTA M.K., WANG G.X., FUJISAKA S., O’NEILL B.T., RAO T.N., WILLOUGHBY J., HARBISON C., FITZGERALD K., ILKAYEVA O., NEWGARD C.B., COHEN D.E. eta KAHN C.R. 2017. «Divergent effects of glucose and fructose on hepatic lipogenesis and insulin signaling». J Clin Invest, 127, 4059-4074.

[13] SOFTIC S., COHEN D.E. eta KAHN C.R. 2016. «Role of Dietary Fructose and Hepatic De Novo Lipogenesis in Fatty Liver Disease». Dig Dis Sci, 61, 1282-1293.

[14] DEREŃ K., WEGHUBER D., CAROLI M. KOLETZKO B., THIVEL D., FRELUT M.L., SOCHA P., GROSSMAN Z., HADJIPANAYIS A., WYSZYŃSKA J. eta MAZUR A. 2019. «Consumption of Sugar-Sweetened Beverages in Paediatric Age: A Position Paper of the European Academy of Paediatrics and the European Childhood Obesity Group». Annals of Nutrition and Metabolism, 74, 296-302.

[15] HANNOU S.A., HASLAM D.E., MCKEOWN N.M. eta HERMAN M.A. 2018. «Fructose metabolism and metabolic disease». J Clin Invest, 128, 545-555.

[16] GALDERISI A., GIANNINI C., VAN NAME M. eta CAPRIO S. 2019. «Fructose Consumption Contributes to Hyperinsulinemia in Adolescents With Obesity Through a GLP-1-Mediated Mechanism». j Clin Endocrinol Metab, 104, 3481-3490.

[17] IPSEN D.J., LYKKESFELDT J. eta TVEDEN-NYBORG P. 2018. «Molecular mechanisms of hepatic lipid accumulation in non-alcoholic fatty liver disease». Cellular and Molecular Life Sciences, 75, 3313-3327.

[18] TER HORST K.W. eta SERLIE M.J. 2017. «Fructose Consumption, Lipogenesis, and Non-Alcoholic Fatty Liver Disease». Nutrients, 9, 981.

[19] KLEINER D.E., BRUNT E.M., VAN NATTA M., BEHLING G., CONTOS M.J., CUMMINGS O.W., FERRELL L.D., LIU Y.C., TORBENSON M.S., UNALP-ARIDA A., YEH M., MCCULLOUGH A.J., SANYAL A.J., eta NONALCOHOLIC STEATOHEPATITIS CLINICAL RESEARCH NETWORK. 2005. «Design and validation of a histological scoring system for nonalcoholic fatty liver disease». Hepatology, 41, 1313-1321.

[20] YOUNOSSI Z., ANSTEE Q.M., MARIETTI M., HARDY T., HENRY L., ESLAM M., GEORGE J. eta BUGIANESI E. 2018. «Global burden of NAFLD and NASH: trends, predictions, risk factors and prevention». Nat Rev Gastroenterol Hepatol, 15, 11-20.

[21] BASARANOGLU M., BASARANOGLU G. eta BUGIANESI E. 2015. «Carbohydrate intake and nonalcoholic fatty liver disease: fructose as a weapon of mass destruction». Hepatobiliary Surg Nutr, 4, 109-116.

[22] HILlGARTNER F.B., SALATI L.M. eta GOODRIDGE A.G. 1995. «Physiological and molecular mechanisms involved in nutritional regulation of fatty acid synthesis». Physiol Rev, 75, 47-76. 
Iñaki Milton-Laskibar, Irene Besné, Helen Carr-Ugarte, María Puy Portillo

[23] JEGATHEESAN P. eta DE BANDT J.P. 2017. «Fructose and NAFLD: The Multifaceted Aspects of Fructose Metabolism». Nutrients, 9, 230.

[24] GÓMEZ-ZORITA S., MILTON-LASKIBAR I., MACARULLA M.T., BIASUTTO L., FERNÁNDEZ-QUINTELA A., MIRANDA J., LASA A., SEGUES N., BUJANDA L., eta PORTILLO M.P. 2021. «Pterostilbene modifies triglyceride metabolism in hepatic steatosis induced by high-fat high-fructose feeding: a comparison with its analog resveratro». Food Funct, 12, 3266-3279.

[25] ENGIN A. 2017. «Non-alcoholic fatty liver disease». Adv Exp Med Biol, 960, 443-467.

[26] BELLANTI F., VILLANI R., FACCIORUSSO A., VENDEMIALE G., SERVIDDIO G. 2017. «Lipid oxidation products in the pathogenesis of nonalcoholic steatohepatitis». Free Radic Biol Med, 111, 173-185.

[27] JEGATHEESAN P., BEUTHEU S., VENTURA G., SARFATI G., NUBRET E., KAPEL N., WALIGORA-DUPRIET A.J., BERHEIM I., CYNOBER L. eta DE BANDT J.P. 2016. «Effect of specific amino acids on hepatic lipid metabolism in fructose-induced non-alcoholic fatty liver disease». Clin Nutr, 35, 175-182.

[28] ARAGONÉS G., GONZÁlEZ-GARCÍA S., AGUILAR C., RICHART C. eta AUGUET T. 2019. «Gut Microbiota-Derived Mediators as Potential Markers in Nonalcoholic Fatty Liver Disease». Biomed Res Int, 2019, 8507583.

[29] LIN W.T., CHAN T.F., HUANG H.L., LEE C.Y., TSAI S., WU P.W., YANG Y.C., WANG T.N. eta LEE C.H. 2016. «Fructose-Rich Beverage Intake and Central Adiposity, Uric Acid, and Pediatric Insulin Resistance». J Pediatr, 171, 90-96.

[30] SCHWARZ J.M., NOWOROLSKI S.M., WEN M.J., DYACHENKO A., PRIOR J.L., WEINBERG M.E., HERRAIZ L.A., TAI V.W., BERGERON N., BERSOT T.P., RAO M.N., SCHAMBELAN M. eta MULLIGAN K. 2015. «Effect of a High-Fructose Weight-Maintaining Diet on Lipogenesis and Liver Fat». J Clin Endocrinol Metab, 100, 2434-2442.

[31] TASKINEN M.R., SÖDERLUND S., BOGL L.H., HAKKARAINEN A., MATIKAINEN N., PIETILÄINEN K.H., RÄSÄNEN S., LUNDBOM N., BJÖRNSON E., ELIASSON B., MANCINA R.M., ROMEO S., ALMÉRAS N., PEPA G.D., VETRANI C., PRINSTER A., ANNUZZI G., RIVELLESE A., DESPRÉS J.P. eta BORÉN J. 2017. «Adverse effects of fructose on cardiometabolic risk factors and hepatic lipid metabolism in subjects with abdominal obesity». J Intern Med, 282, 187-201.

[32] DOMÍNGUEZ-COELLO S., CARRILLO-FERNÁNDEZ L., GOBIERNOHERNÁNDEZ J., MÉNDEZ-ABAD M., BORGES-ÁLAMO C., GARCÍADOPICO J.A., AGUIRRE-JAIME A. eta CABRERA-DE LEÓN A. 2020. «Decreased Consumption of Added Fructose Reduces Waist Circumference and Blood Glucose Concentration in Patients with Overweight and Obesity. The DISFRUTE Study: A Randomised Trial in Primary Care». Nutrients, 12,1149 . 
[33] CATALANO K.J., MADDUX B.A., SZARY J., YOUNGREN J.F., GOLDFINE I.D. eta SCHAUFELE F. 2014. «Insulin Resistance Induced by Hyperinsulinemia Coincides with a Persistent Alteration at the Insulin Receptor Tyrosine Kinase Domain». PLoS One, 9, e108693.

[34] PAN H., YAN D., XU M., LI F., REN M., ZHANG J. eta WU M. 2019. «Interaction Between Lactate and Uric Acid is Associated With a Higher Prevalence of Metabolic Syndrome: A Community-Based Study». Exp Clin Endocrinol Diabetes, 127, 557-566.

[35] HU Y., ZHAO H., LU J., XIE D., WANG Q., HUANG T., XIN H., HISATOME I., YAMAMOTO T., WANG W. eta CHENG J. 2021. «High uric acid promotes dysfunction in pancreatic $\beta$ cells by blocking IRS2/AKT signalling». Molecular and Cellular Endocrinology, 520, 111070.

[36] SOFTIC S., STANHOPE K.L., BOUCHER J., DIVANOVIC S., LANASPA M.A. JOHNSON R.J. eta KAHN C.R. 2020. «Fructose and hepatic insulin resistance». Crit Rev Clin Lab Sci, 57, 308-322.

[37] SOFTIC S., MEYER J.G., WANG G.X., GUPTA M.K., BATISTA T.M., LAURITZEN H.P.M.M., FUJISAKA S., SERRA D., HERRERO L., WILLOUGHBY J., FITZGERALD K., ILKAYEVA O., NEWGARD C.B., GIBSON B.W., SCHILLING B., COHEN D.E., eta KAHN C.R. 2019. «Dietary Sugars Alter Hepatic Fatty Acid Oxidation via Transcriptional and Post-translational Modifications of Mitochondrial Proteins». Cell Metab, 30, 735-753.

[38] CHEN L., CHEN R., WANG H. eta LIANG F. 2015. «Mechanisms Linking Inflammation to Insulin Resistance». Int J Endocrinol, 2015, 508409.

[39] WANG H., SUN R.Q., ZENG X.Y., ZHOU X., LI S., JO E., MOLERO J.C. eta YE J.M. 2015. «Restoration of autophagy alleviates hepatic ER stress and impaired insulin signalling transduction in high fructose-fed male mice». Endocrinology, 156, 169-81.

[40] ZDROJEWICZ Z., POPOWICZ E., SZYCA M., MICHALIK T. eta ŚMIESZNIAK B. 2017. «TOFI phenotype - its effect on the occurrence of diabetes». Pediatr Endocrinol Diabetes Metab, 23, 96-100.

[41] LONDON E. eta CASTONGUAY T.W. 2011. «High Fructose Diets Increase $11 \beta$-Hydroxysteroid Dehydrogenase Type 1 in Liver and Visceral Adipose in Rats Within 24-h Exposure». Obesity, 19, 925-932.

[42] MAREK G., PANNU V., SHANMUGHAM P., PANCIONE B., MASCIA D., CROSSON S., ISHIMOTO T. eta SAUTIN Y.Y. 2015. «Adiponectin Resistance and Proinflammatory Changes in the Visceral Adipose Tissue Induced by Fructose Consumption via Ketohexokinase-Dependent Pathway». Diabetes, 64, 508-518.

[43] KOPIN L. eta LOWENSTEIN C. 2017. «Dyslipidemia». Ann Intern Med, 167, ITC81-ITC96.

[44] BRASCIANO H., FEDERICO L. eta ADELI K. 2005. «Fructose, insulin resistance, and metabolic dyslipidemia». Nutr Metab (Lond), 2, 5.

[45] MAYES P.A. 1993. «Intermediary metabolism of fructose». Am J Clin Nutr, 58, 754S-765S. 
Iñaki Milton-Laskibar, Irene Besné, Helen Carr-Ugarte, María Puy Portillo

[46] MOORADIAN A.D. 2009. «Dyslipidemia in type 2 diabetes mellitus». Nat Clin Pract Endocrinol Metab, 5, 150-159.

[47] STANHOPE K.L., MEDICI V., BREMER A.A., LEE V., LAM H.D., NUNEZ M.V., CHEN G.X., KEIM N.L. ETA HAVEL P.J. 2015. «A dose-response study of consuming high-fructose corn syrup-sweetened beverages on lipid/lipoprotein risk factors for cardiovascular disease in young adults». Am J Clin Nutr, 101, 1144-1154. 